\title{
A Fuzzy-based Approach for Energy Management of DHW Systems in Hotels
}

\author{
M. Llano ${ }^{a}$, R. Mesa-Cruz ${ }^{a}$, A. Hamilton ${ }^{a}$, J. Acosta ${ }^{b}$ and J. A. Mendez Perez ${ }^{a}$ \\ aDepartamento de Ingeniería Informática y de Sistemas, Universidad de La Laguna, La Laguna, Spain, \\ rmesacru@ull.edu.es

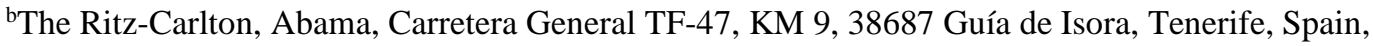 \\ juanfrancisco.acosta@ ritzcarlton.com
}

\begin{abstract}
This paper focuses on the intelligent management of domestic hot water (DHW) systems in buildings. Thermal installations are studied in depth due to the high percentage they represent in energy consumption, moreover, they usually lack management systems. To address this problem, firstly a functional model of a DHW installation is created, then a study is carried out on the current management model applied and the energy losses that it entails. Once this is achieved, a proposal is made for an intelligent management system based on fuzzy logic that controls resources automatically to improve its efficiency. The system is validated by applying it to real data obtained from a high-end hotel in the island of Tenerife.
\end{abstract}

Keywords: Energy efficiency, Energy management systems, Fuzzy control, Hotel energy efficiency, Domestic hot water.

\section{Introduction}

In 2020, the period agreed by the leaders of the European Union in 2007 to reduce greenhouse gas emissions ended [8]. This Directive also involves the introduction of a set of binding measures to help Member States achieve this objective and provides legally binding rules for end users and energy providers. Additional energy efficiency standards for products and buildings were introduced through the Ecodesign Directives (2009/125 / EC) [6], Energy Efficiency Labeling (2010/30 / EU), updated in 2017 (2017/1369 / EU) [9], and the energy efficiency of buildings (2010/31 / EU) [7]. In 2019, as part of the
"Clean Energy for all Europeans" package of measures, a new goal was set to reduce energy consumption by at least $32.5 \%$ by the 2030 horizon [16].

In 2012, 19149 hotel establishments operated in Spain, with 1.84 million beds, according to the Balantur report from TourSpain [7]. Hotel facilities are among the top five in terms of energy consumption in the tertiary sector. Most of this energy is derived from fossil fuels, so the contribution of the hotel sector to global warming and climate change is estimated between 160 and $200 \mathrm{~kg}$ of $\mathrm{CO}_{2}$ per year per square meter of room surface [1].

Despite the importance of energy consumption in hotels and the opportunity to improve efficiency they present, few studies have been found in the consulted literature specifically focused on energy management of this type of buildings [2], [1].

The dynamics of energy systems in buildings can be described by approximation with different models, depending on the specific purpose of the analysis developed, which can range from simulation in the design phase to energy management [4]. The energy management problem is usually approached as a control problem [5].

The use of fuzzy logic in the field of energy management in hotels has been very limited. Several authors have used it in making decisions for the choice of energy saving technologies [12] or for selecting the best cogeneration system to use in a hotel [13]. Intelligent prediction systems using neurofuzzy have been designed for the prediction of energy consumption in buildings and applied to hotels [11].

There are some works that use fuzzy control to determine thermal conditions, as is the case of Patil C. et al. [14] who apply it to an air conditioning Split, or 
the development of Gouda M. el al. [15] that uses fuzzy control to achieve the satisfaction of the greatest number of customers regarding the temperature of the air conditioning system in a common area. In none of these cases is energy saving among their main objectives.

This work provides a fuzzy control system for the management of DHW systems in hotels in order to reduce energy consumption. The study includes a detailed modelling of the DHW facilities to determine the main variables and the main sources of energy losses. The proposal analyzes the main variables affecting consumption and proposes a methodology based on intelligent control to improve the performance of the system. The efficiency of the proposal is validated using data from a real hotel.

\section{System description}

In this paper, a typical centralized Domestic Hot Water (DHW) production system has been considered. This kind of installation can be commonly found in a great number of hotels, as well as in many other facilities.

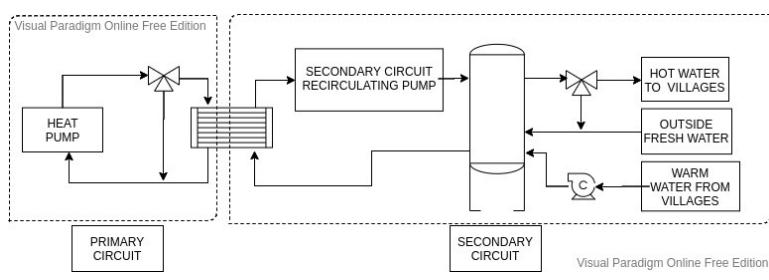

Figure 1. Generic centralized domestic hot water production system.

This DHW system, as most of centralized heat production systems, is divided into two different piping subsystems: primary and secondary, with hydraulic separation between both. Primary piping is a closed loop with treated water inside, in order to extend equipments' lifespan. On the other hand, the secondary piping is an open loop circuit to transport DHW from the production site to the consumption points. Since water in the secondary system is not previously treated, equipment installed in it must be much more robust.

The main equipment found in the primary piping would be: heat pump, circulator pump and 3-way valve. As for the secondary piping, usual equipment consists of: heat exchanger, circulator pump, storage tank, mixing valve and hot water recirculating pump.

Primary circulator pumps make water flow from the heat pump to the heat exchangers. Water circulation is controlled by the heat demand. 3-way valves are installed before each heat exchanger, to adjust water flow according to the average temperature inside the storage tank. When no heat is needed, these valves are totally closed, to avoid heat losses through the heat exchangers.

Water circulation between heat exchangers and storage tanks is made by the secondary circulator pumps. Hot water mixing valves are installed after the storage tanks, to adjust water temperature in the outlet line to the desired comfort value. They are 3-way valves whose inputs are water from the storage tank and fresh water and whose output goes to consumption at the chosen temperature. There, DHW from the storage tanks is mixed with fresh water from outside.

Finally, hot water recirculating pumps are used to keep a small hot water flow rate constantly circulating through the distribution piping, with the aim of preventing water temperature inside the system to fall due to thermal losses.

\section{Problem description}

\subsection{General scope}

In this type of facilities, DHW production system is operating 24 hours a day, except for the annual maintenance operations for Legionellosis prevention. Temperature setpoints are kept without variation even when DHW demand is null (i.e., even during late-night periods). This leads to significant heat losses and a great energy consumption.

System setpoints configuration is usually fixed and the aim of this work has been to develop an automated management system capable of varying the system operation conditions to move towards a less energy wasting functioning.

First, a generic computer model, using a combination of Matlab tools like Simscape/Simulink and specific scripts developed for the model, has been built for the system, and several simulations have been performed to try to determine the influence of each of the main variables involved in its energy consumption. The results are analyzed below.

\subsection{Recirculation flow rate}

Three different recirculation flow rate set points were simulated. As a conclusion, we can establish that a lower recirculation flow rate implies a lower operating time for the heat pump, and thus a lower energy consumption, provided that a reasonable temperature fall in the storage tanks can be allowed. 


\subsection{Hot water distribution temperature}

Water distribution temperature is set by the 3-way mixing valve. Since part of the distributed water is returned to the storage tank, a low distribution temperature can be considered as a perturbation for the control of the water temperature inside the tank. Thus, a higher distribution temperature can contribute to energy savings.

\subsection{Hot water storage tank temperature}

Water storage temperature optimization is key to reach a balance between energy consumption and user comfort. A lower set point will lessen the first one, but the second one must be always fulfilled.

\subsection{Primary piping flow rate}

As primary piping flow rate increases, so does storage tank heating speed. Besides, primary and secondary flow rates in the heat exchanger should be as close as possible to optimize heat exchange efficiency.

\subsection{Heat pump}

Operation time for the heat pump should be as low as possible, to improve the system energy efficiency, since this is the main energy consumption equipment at the installation. Water temperature in the primary piping is key to this goal.

\subsection{Thermal losses in the distribution piping}

In the DHW distribution piping, due to the continuous circulation of the water, there is heat dissipation between the pipe and the environment, which is a function of both the circulating flow and the water temperature. Figure 2 shows the relationship between distribution temperature and thermal losses, while Figure 3 shows the relationship between recirculation rate and thermal losses.

It can be noticed how the variation in the distribution temperature has a greater impact on the thermal losses of the system than the variation in the recirculation flow rate.

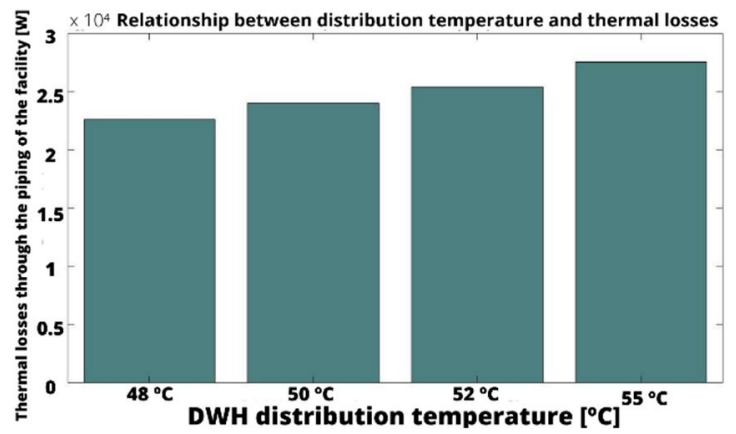

Figure 2: Relationship between distribution temperature and thermal losses.

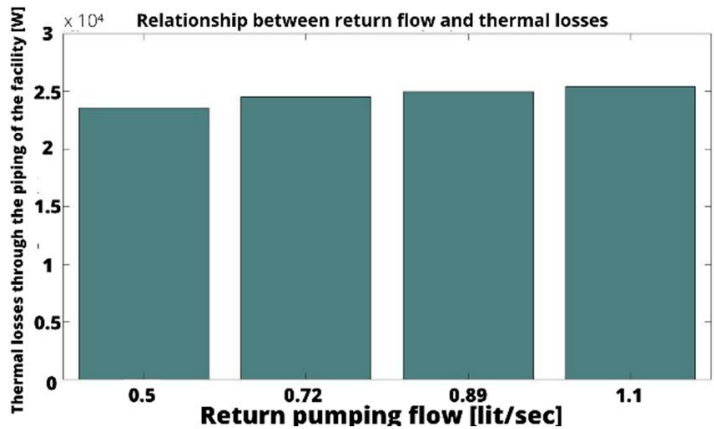

Figure 3: Relationship between return flow and thermal losses.

\section{$4 \quad$ Fuzzy intelligent proposal for energy efficiency}

\subsection{Management system design}

The strategy proposed to carry out the optimization of all the variables previously described consists of implementing a system capable of making the correct decisions, depending on the state of the installation. It will be able to identify the situation of the installation and to adjust the different set points to bring the system to a point of maximum efficiency. To this purpose, the system will need to constantly read the values of the several variables of interest and to act on the correct control variables.

In order to automate the decision-making tasks, the system will be based on fuzzy logic, considering that this way it will be easy and quick to implement. Another one of the advantages of this kind of systems is that they do not need to have a mathematical model of the installation to be controlled, thereby speeding up the implementation process.

\subsection{System input variables}

Input variables set should be as short as possible, due to computational power reasons. Likewise, by reading this set of variables, the control system should be able to inform us, at every moment, about the state of the installation and to infer which operating point should it be moved towards.

Variables selected for the system are: day time, instant demand, control error and tank temperature rank.

Day time is an input variable, since DHW demand usually depends on the moment of the day. A vast majority of facilities have demand peaks in certain 
time slots, usually in the morning and/or in the afternoon.

\subsection{System output variables}

As output variables, those which directly affect the process when modified are the ones that have been chosen: storage tank temperature, mixing valve and recirculation pump temperature set points in the secondary piping; and heat pump and 3-way primary valve set points in the primary piping.

\subsection{Inference system rules generation}

Once the input and output variables for our system have been defined the THEN-IF rules that will form the heart of the fuzzy inference system must be established. This step in the design of the management system must be carried out with expert knowledge of the installation, therefore each facility will have an exclusive set of rules to define it. In the general case, a system with four input variables and five output variables could be considered, as shown in Figure 4.

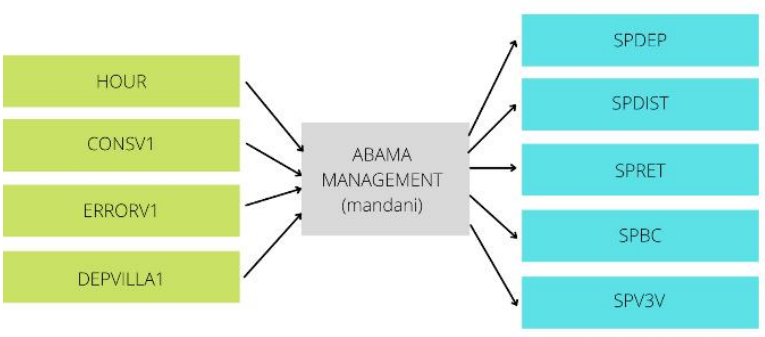

Figure 4: Fuzzy management system sketch.

As explained before, the desired performance for each of these variables has been determined based on the simulations carried out, along with the experience from the hotel facility management staff. This is further discussed in the paragraphs below.

\section{a) Storage tank temperature set point}

Storage tank temperature set point will vary according to the moment of the day and the DHW demand. This variable will be controlled with a certain hysteresis. During the period with low or null demand, this hysteresis will be higher; on the other hand, during periods of high demand, hysteresis will be lower.

\section{b) Mixing valve set point}

The mixing valve is used for setting the temperature at which the DHW is distributed to the consumers. With this variable, special care must be taken as it greatly affects the average temperature of the tank and therefore subtracts thermal energy from the system. One way for the system to gain in efficiency is to maintain the distribution temperature as close as possible to the tank temperature setpoint.

\section{c) Recirculation pump set point}

The recirculation pump has an essential role in any centralized DHW system, since its flow rate affects the storage tank temperature.

\section{d) Heat pump set point}

One of our main goals will be to lessen the operation time for the heat pump, since it accounts for $90 \%$ of the whole energy consumption in the system.

\section{e) 3-way primary valve set point}

The 3-way valve controls the water flow circulating through the primary circuit of the heat exchanger, depending on the temperature set point for the storage tank. It must be noticed that a maximum flow does not always imply a shorter heating time since other factors can affect it, such as the type and characteristics of the heat exchanger or the flow rate through the secondary piping.

Based on the set points selected, the general system would result in a total of 74 rules.
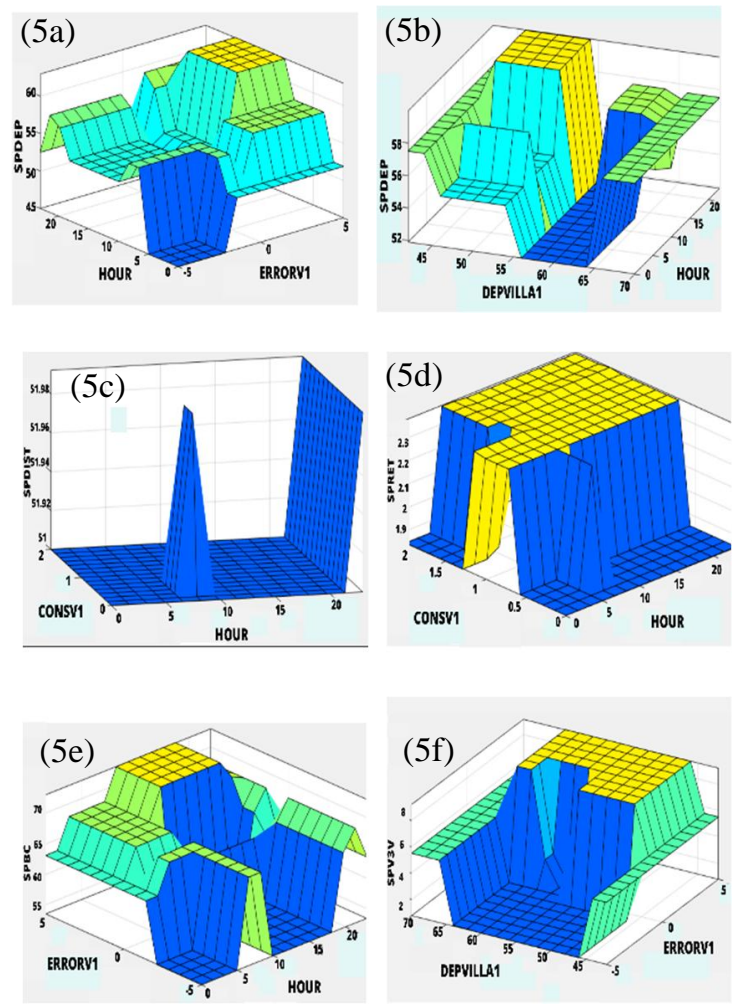

Figures $5 a$ to $5 f$ : Control surfaces generated by the rules definition for the system. 
Control surfaces resulting from the definition of these specific rules for the installation studied are shown in figures $5 \mathrm{a}$ to $5 \mathrm{f}$.

Figure 5a shows how the tank temperature setpoint is adjusted taking into account the hour of the day and the error between the process variable and the setpoint itself. In order to understand the surface we can take as a reference the middle of the ERRORV1 axis. The lefthand side values of the axis corresponds to the situation where the process variable is larger than the setpoint(cooling process) and therefore establishes the lower limits the temperature can reach according to the hour of the day. It is mandatory not to go below this lower limits to ensure human comfort. Towards the right side, figure represents the heating process when the physical variable is lower than the fixed setpoint, so heating the tank is necessary.

Figure $5 b$ shows the same variable SPDEP but depending on the hour of the day and, on the other side, the interval in which the tank temperature falls (three zones). The last variable was necessary to introduce it because, when the system shifted between different demand zones depending on the hour of the day, it was required to know where the tank temperature was. There are three zones: values below $56^{\circ} \mathrm{C}$ belong to an interval where the facility is not giving service and the therefore the temperature remains low; values between $56^{\circ} \mathrm{C}$ and $60,5^{\circ} \mathrm{C}$ are the ones corresponding to the normal service performance; and values between $60^{\circ} \mathrm{C}$ and $65^{\circ} \mathrm{C}$ correspond to non-service with high temperature. As it can be seen, the hour of the day is the variable with the biggest weight due to the strong link between it and DHW demand.

Figure 5c shows how the distribution setpoint varies according to the hour of the day and the instantaneous consumption of the facility. As a rule, the distribution temperature should not be changed without a reason because it affects comfort. Although sometimes the hotel facilities have non-programmed events in which the system has to match a demand that was not scheduled, otherwise it should remain constant.

Figure 5d lets us see the behavior of the return flow setpoint according to the hour of the day and the instantaneous consumption of the facility. The return flow should also be maintained in a constant value as long as the system does not change its performance, since this return flow affects as a big temperature perturbation for the tank. Therefore, the whole range of return flow values that the pumps could reach was analyzed by simulations, depending on the hour of the day.
The heat pump is the equipment that consumes the vast majority of the energy. For this reason, the temperature on the primary circuit has to be controlled and adjusted according to the scheduled demand. There are two valley zones (blue areas) which correspond to low DHW demand either because of the hour or the actual error of the tank temperature. These are the lowest values that can be reached. On the other hand, when there is a high demand forecast or the tank temperature is below the expected value, this setpoint is fixed at a higher value (figure 5e)

Finally, figure $5 f$ gathers the performance of the 3-way primary valve. This variable performance varies depending on how many secondary circuits the primary circuit gives service to. When there is only one secondary circuit, its performance is similar to that of the heat pump, but when more than one secondary circuits are working, its position is regulated mainly by the tank temperature range and the process error, opening when the tank has to be heated (yellow area) and closing when there is enough thermal energy stored in the tank to match the instant demand by itself (blue area).

As control surfaces show, the axis corresponding to the Daily Hour variable exhibits certain dynamics. The reason for the automated system to perform like this is because the main problem found in the current installation is the huge amount of electric energy turned into heat that is being wasted because of the lack of DHW demand during some periods. Furthermore, hot water instant demand from clients is another variable which plays a big role in the control of the setpoints since it gives important information about the unexpected consumption events.

\section{Case of study}

Once the simulation model and the fuzzy control system have been developed, a real 5 Stars Hotel in the South of Tenerife (Canary Islands, Spain) has been selected to test it, as a case of study. The hotel has a centralized DWH production system like the generic one described above, but with the particularity that the secondary piping is divided into five subsystems, each of which serve one fraction of the hotel's rooms.

Primary piping has $5,15 \mathrm{~m}^{3}$ of water, supplying heat to five secondary DHW substations. The heat pump model is AERMEC WWB0900XHL, with a heating power of $256,6 \mathrm{~kW}$ (electrical power supply of 65,5 $\mathrm{kW})$.

Heat exchangers are Alfa-Laval, model M3, with 18 plates and a volume of 1,5 1 . 
Each DWH substation has two $5 \mathrm{~m}^{3}$ storage tanks, which can be combined either in parallel or series connection, although literature suggests that series connection is better [10][13. Two pumps are installed for each DHW substation, in a parallel set up and alternate operation. Recirculation pumps have a maximum flow of $6.6 \mathrm{~m}^{3} / \mathrm{h}$.

The whole system is controlled by the Building Management System (BMS) and monitored by a SCADA.

System set points configuration are fixed as shown in table 2 .

\begin{tabular}{|c|c|}
\hline Variable & Magnitude \\
\hline Primary circuit temperature & $70^{\circ} \mathrm{C}$ \\
Hot water tank temperature & $60^{\circ} \mathrm{C}$ \\
Distribution temperature & $55^{\circ} \mathrm{C}$ \\
Return flow temperature & $51.3^{\circ} \mathrm{C}$ \\
Secondary circuit circulating pump hysteresis & $4{ }^{\circ} \mathrm{C}$ \\
Return flow pump without control & $6.6 \mathrm{~m}^{3} / \mathrm{h}$ \\
\hline
\end{tabular}

Table 1: Current DHW system setpoints.

An energy study has been carried out for one of the DHW substations, assuming that the results can be extrapolated to the rest of the hotel. Daily energy consumed for DHW production in the substation tourns out to be a total of $299,45 \mathrm{kWh} / \mathrm{d}$, with 267,84 $\mathrm{kW} / \mathrm{d}$ for the heat pump, $18,2 \mathrm{kWh} / \mathrm{d}$ corresponding to the recirculation pump and $10,7 \mathrm{hWh}$ for the secondary piping pump.

\section{Results}

The designed automated management system has been simulated for this hotel's DHW installation and then applied to the actual facility.

Due to computational power limitations, simulations were divided into five blocks:

- Night and early morning hours.

- Transition from early morning demand hours.

- Evening hours when there is no demand.

- Evening demand hours.

Besides, a fifth simulation has been carried out to show the system's response to a change in the instant demand.

One of the most relevant results, regarding the set points, is that the system can keep the storage tank temperature high enough to ensure users comfort during periods of demand peaks (considering the water heating time required for the installation), but at the same time it gets rid of the need of keeping this temperature fixed during low or null demand periods.

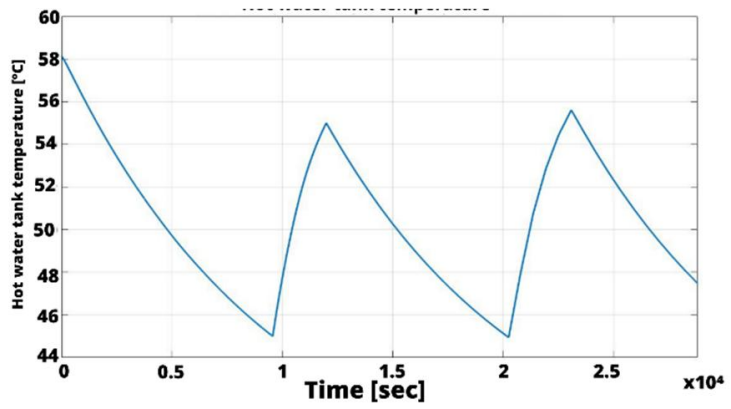

Figure 6: Storage tank temperature evolution.

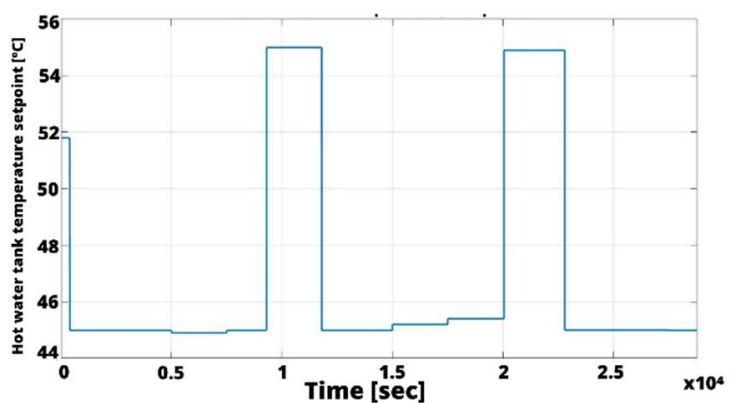

Figure 7: Storage tank temperature set point simulation.

Closely related to this, another relevant result found is that heat pump set point can be flexible, which has a great impact in the system energy consumption, being heat pump the greatest energy consumer in the installation.

Furthermore, simulations show how recirculation flow rate can be varied depending on hot water instant demand, thus lessening energy consumption from the recirculation pump.

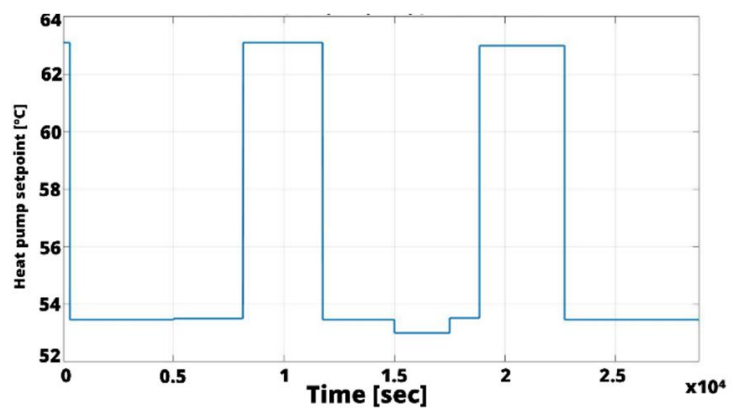

Figure 8: Heat pump set point simulation. 


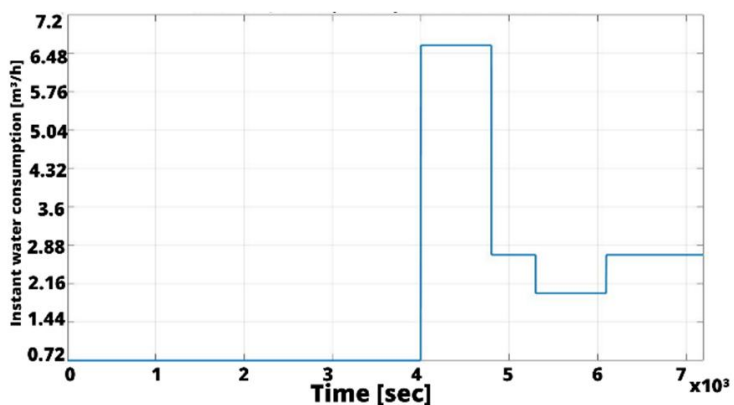

Figure 9: Hot water instant demand simulation.

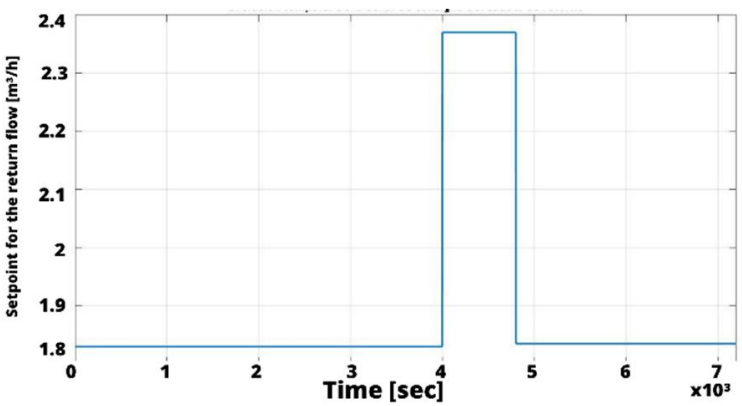

Figure 10: Recirculation flow rate setpoint simulation.

Finally, results obtained from the simulations of the automatic decision-making system about energy consumption can be seen in tables 3 to 5 .

\begin{tabular}{|l|c|c|}
\hline \multicolumn{1}{|c|}{ Equipment } & $\begin{array}{c}\text { ON time } \\
{[\mathbf{h}]}\end{array}$ & $\begin{array}{c}\text { Energy } \\
{[\mathbf{k W h}]}\end{array}$ \\
\hline Return flow pump & 8 & 5.1 \\
Secondary piping pump & 1.28 & 0.97 \\
Heat pump & 2.75 & 25.68 \\
\hline \multicolumn{1}{|c|}{ Total } & & $\mathbf{3 1 . 7 5}$ \\
\hline
\end{tabular}

Table 2: Energy consumption between 22:00 h and 6:00 $\mathrm{h}$ with an automatized management system.

\begin{tabular}{|l|c|}
\hline \multicolumn{1}{|c|}{ Time interval } & $\begin{array}{c}\text { Energy } \\
{[\mathbf{k W h}]}\end{array}$ \\
\hline Morning setting up & 8.37 \\
Morning high demand & 24.4 \\
Afternoon low demand & 80.2 \\
Afternoon high demand & 25.6 \\
Night low demand & 12.9 \\
\hline \multicolumn{1}{|c|}{ Total } & $\mathbf{1 5 1 . 4 7}$ \\
\hline
\end{tabular}

Table 3: Energy consumption between 6:00 $\mathrm{h}$ and 22:00 h with an automatized management policy.

\begin{tabular}{|l|c|c|}
\hline \multicolumn{1}{|c|}{ Facility management } & $\begin{array}{c}\text { Energy } \\
\text { consumption } \\
{[\mathbf{k W h}]}\end{array}$ & Costs [€] \\
\hline Current management policy & 107802 & 10115.06 \\
Automatized management policy & 65959.2 & 6188.95 \\
\hline
\end{tabular}

Table 4: Annual costs comparison between the current management and the automatized management.

Results show potential annual savings of $39 \%$ in terms of energy and almost $4.000 €$ of cost reduction for the DHW production system for each substation. This would lead to an annual energy saving of around $166.000 \mathrm{kWh}$ and $16.000 €$ for the whole hotel.

Since storage tank temperature set point is always over $45^{\circ} \mathrm{C}$, human comfort is guaranteed as long as thermal losses in the distribution pipes are kept very low. However, a further assessment on water temperature in some of the final consumption points could be developed in order to ensure this, and in case of unfulfillment, a higher low temperature constraint for the tank could be set.

In relation to the controller behavior, at first sight it could be considered that the fuzzy controller with 74 rules behaves nearly as a simple on/off strategy (setpoints vary very little and are mainly based on two points of operation). However, a closer look reveals that the two main setpoint stages are highly marked by the DHW demand peaks, typical from this kind of infrastructures; but also, during the periods between demand peaks, a slight setpoint variation is shown, to adapt to the demand changes.

\section{Conclusions}

An automated management system, based on fuzzy logic, has been proposed as a method to improve performance for centralized domestic hot water production systems, with energy saving as the ultimate goal.

To this end, a generic model has been built for the system, to identify the main variables affecting the energy consumption. Based on this information, input and output variables have been selected and the fuzzy inference system rules have been developed.

Simulations carried out for the automated management system developed, contrasted with the data gathered from the simulations, have proven that this kind of system may be useful to save energy in DHW centralized production installations. The response has been as expected since it moves the operating point towards a more efficient state. However, a deeper study should be needed to reach an absolute optimal 
operating point for the installation. In this sense, further improvements in the design of the fuzzy controller can be done. In particular, the inclusion of detailed analysis to show the relationship of feature vectors with labels will help to determine the relationship between features and the contribution of each feature in the inference mechanism.

Although the results obtained in this work are satisfactory, in future works it would be also interesting to study the performance of optimal control strategies based on predictive control (MPC). For this, it is necessary to to continue expanding the knowledge on centralized domestic hot water and air conditioning systems. This is necessary to synthesize models with enough accuracy that can be included in MPC strategies.

\section{Acknowledgement}

The authors thank Hotel Ritz-Carlton Abama for their valuable technical assistance in the modelling aspects of this work.

\section{References}

[1] "Analysis on Energy Use by European Hotels: Online Survey and Desk Research, Hotel Energy Solutions project publications." 2011.

[2] M. Chung and H.-C. Park, "Comparison of building energy demand for hotels, hospitals, and offices in Korea," Energy, vol. 92, pp. 383-393, Dec. 2015.

[3] S. M. Smitt, "Integrated Energy concepts for high performance hotel buildings," no. June, 2017.

[4] L. Tronchin and M. Manfren, "Energy Network Modelling Approaches for Multi-Scale Building Performance Optimization," in Proceedings 2018 IEEE International Conference on Environment and Electrical Engineering and 2018 IEEE Industrial and Commercial Power Systems Europe, EEEIC/I and CPS Europe 2018, 2018.

[5] A. Acosta, A. I. González, J. M. Zamarreño, and V. Álvarez, "Energy savings and guaranteed thermal comfort in hotel rooms through nonlinear model predictive controllers," Energy Build., vol. 129, pp. 59-68, Oct. 2016.

[6] European Parliament. "DIRECTIVE 2009/125/EC OF THE EUROPEAN PARLIAMENT AND OF THE COUNCIL establishing a framework for the setting of ecodesign requirements for energy-related products". En: Official Journal of the European Union 52 (2009). doi: doi:10.3000/17252555.L_2009.285.eng.

[7] European Parliament. "DIRECTIVE 2010/31/EU OF THE EUROPEAN PARLIAMENT AND OF
THE COUNCIL on the energy performance of buildings". En: Official Journal of the European Union 53 (2010). doi: http://data.europa.eu/eli/dir/2010/31/oj.

[8] European Parliament. "DIRECTIVE 2012/27/EU OF THE EUROPEAN PARLIAMENT AND OF THECOUNCIL, on energy efficiency, amending Directives 2009/125/EC and 2010/30/EU and repealing Di-rectives 2004/8/EC and 2006/32/EC". En: Official Journal of the European Union 55 (2012). doi: 10.3000/19770677.L_2012.315.eng.127

[9] European Parliament. "REGULATION (EU) 2017/1369 OF THE EUROPEAN PARLIAMENT ANDOF THE COUNCIL setting a framework for energy labelling and repealing Directive 2010/30/EU". En:Official Journal of the European Union 60 (2017). doi: http://data.europa.eu/eli/reg/2017/1369/oj.

[10] A. Campos Celador, M. Odriozola y J.M. Sala. Implications of the modelling of stratified hot water storage tanks in the simulation of CHP plants". En: Energy Conversion and Management 52 (2011). doi:https://doi.org/10.1016/j.enconman.2011.04. 015

[11] K. Li and H. Su, "Forecasting building energy consumption with hybrid genetic algorithmhierarchical adaptive network-based fuzzy inference system,” Energy Build., vol. 42, no. 11, pp. 2070-2076, Nov. 2010.

[12] A. Mardani, E. K. Zavadskas, D. Streimikiene, A. Jusoh, K. M. D. Nor, and M. Khoshnoudi, "Using fuzzy multiple criteria decision making approaches for evaluating energy saving technologies and solutions in five star hotels: A new hierarchical framework," Energy, vol. 117, pp. 131-148, Dec. 2016.

[13] P. Alcan, A. Balin, and H. Başligil, "Fuzzy multicriteria selection among cogeneration systems: A real case application," Energy Build., vol. 67, pp. 624-634, Dec. 2013.

[14] C. B. Patil and R. R. Mudholkar, "Design and Implementation of Genetic Fuzzy Controller for Split Air-Conditioner Control Based on Fanger's PMV Index," Int. J. Air-Conditioning Refrig., vol. 27, no. 4, Dec. 2019.

[15] M. M. Gouda, S. Danaher, and C. P. Underwood, "Thermal comfort based fuzzy logic controller," Build. Serv. Eng. Res. Technol., vol. 22, no. 4, pp. 237-253, Nov. 2001.

[16] European Union. (2019). Clean energy for all Europeans - Publications Office of the EU. https://doi.org/10.2833/21366 